\title{
Cultivation of microalgae euglena gracilis: mixotrophic growth in photobioreactor
}

\begin{abstract}
Microalgae Euglena gracilis was used for lipid production. Photo-mixotrophic cultivation was done in self-constructed photobioreactor. During cultivation carbon source, stirrer speed, aeration rate and light source were changed to provide suitable cultivation condition for algae biomass and lipid production. It was find out that the changing from heterotrophic to autotrophic condition increase lipid production. Stirrer speed and aeration rate has a more pronounced effect on the biomass production. Due to the optimization of cultivation conditions, lipid production was increased from $0.4 \%$ to $30 \%$ of biomass dry weight in a single bioreactor. During autotrophic cultivation $\mathrm{CO}_{2}$ increase lipid production in the E. gracilis cells but it has negative impact on the biomass production.
\end{abstract}

Keywords: photo-mixotrophic cultivation, euglena gracilis, lipid production, cultivation conditions, photobioreactor
Volume 4 Issue 5 - 2017

\author{
Božidar Šantek, Tonči Rezić* \\ Department of Biochemical Engineering, University of Zagreb, \\ Croatia
}

Correspondence: Tonči Rezić, Department of Biochemical Engineering, Faculty of Food Technology and Biotechnology, University of Zagreb, Pierottijeva 6/IV, HR-10000 Zagreb, Croatia, Tel +385 | 4605 056, Fax +385 | 4836424 , Email trezic@pbf.hr

Received: April 18, 2017 | Published: July 17, 2017

\section{Introduction}

Many studies have been performed to explore the techniques for production large quantities of microalgae biomass. Two type of bioreactors and cultivation techniques are usually used to growth microalgae: open raceway pond system and closed Photobioreactor system. ${ }^{1,2}$ Disadvantages of the open pond system is: limitation in controlling contaminations and less control of process parameters on the other hand photo bioreactors provide an easy system of controlling nutrients for growth, cultivation parameters such as temperature, dissolved $\mathrm{CO}_{2}$ and $\mathrm{pH}$, and to prevent contaminations. However, photo bioreactors have a high capital and operational costs. ${ }^{3}$ Therefore, selection of microalgae production techniques is an important factor to be considered for the efficient production of a microalgal species.

Microalgae are an important source of vitamins, minerals, proteins, lipids, antioxidants and can be use as valuable nutrients in the human and cattle feeding products. ${ }^{4}$ Some microalgae species can accumulate high levels of lipids which can be used as valuable food supplements. Additionally, lipids can be transesterified into biodiesel. ${ }^{5}$

Microalgae are also interesting microorganisms for the ecological and environmental issues, such as the greenhouse effect and industrial water pollution. Carbon dioxide released from power plants can be used as the carbon source for microalgae growth and production of valuable nutrients efficiency at a minimal cost. ${ }^{6}$

In this investigation Euglena gracilis photo-mixotrophic cultivation was done in modified stirred tank bioreactor. Optimization of light source and carbon sources was applied in order to increase algae biomass and lipid production. The second focus was on potential of Euglena gracilis to growth phototrophic and fixates $\mathrm{CO}_{2}$ as main carbon source.

\section{Materials and methods}

\section{Algae strain, media and cultivation conditions}

Euglena gracilis 1224-5/25 from Sammlung von Algenkulturen
Götting was used in all experiments. E. gracilis inoculum cultures were grown for $72 \mathrm{~h}$ at $28^{\circ} \mathrm{C}$ in $500 \mathrm{~mL}$ Erlenmeyer flasks filled with $200 \mathrm{~mL}$ of a liquid medium prepared according Hutner medium.

\section{Bioprocess operations}

Photomixotrophic batch-cultivation were performed in a $2 \mathrm{~L}$ bioreactor (Biostat MD, B. Braun, Germany) with a working volume of $1 \mathrm{~L}$. Bioreactor was equipped with four lamp located vertically around bioreactor vessel, at the $5 \mathrm{~cm}$ distance from the surface of bioreactor to provided continuous light to the system. Two different light source was used: Sun-glo lamp Hagen-Deutschland, Japan, 15W, lux80, 4500K and Aqua-glo lamp Hagen-Deutschland, Japan, 15W, lux $80,4500 \mathrm{~K} .900 \mathrm{~mL}$ of a Hutner medium was added to the reactor and autoclaved for $20 \mathrm{~min}$ at $121^{\circ} \mathrm{C}$. After cooling, cultivation was started by the addition of the inoculums culture and the temperature was maintained at $28^{\circ} \mathrm{C}$. The stirrer speed was in the range from 1001/ $\min$ to $3001 / \mathrm{min}$. The aeration rate was changed from 127 to $800 \mathrm{~mL} /$ min. After $120 \mathrm{~h}$ of heterotrophic cultivation glucose and organic acids was depilated and autotrophic growth condition was started. During autotrophic growth, the effect of increase $\mathrm{CO}_{2}$ concentration on biomass and lipids production was investigated. By taking into account the $\mathrm{CO}_{2}$ concentration in the air is about $0.03 \%$, during autotrophic growth $\mathrm{CO}_{2}$ concentration was increase to $3 \%$. The initial E. gracilis cell number in the bioreactor was $5 \cdot 10^{5} \mathrm{cell} / \mathrm{mL}$. The $\mathrm{pH}$ was monitored but was allowed to float freely during the fermentation.

\section{Analysis}

Total lipid analysis: Cells were harvested by centrifugation at $4500 \mathrm{rpm}$ for $5 \mathrm{~min}$ at $4^{\circ} \mathrm{C}$. After centrifugation samples were extracted with chloroform-methanol-water $\quad(1: 2: 0.8, \quad \mathrm{v} / \mathrm{v} / \mathrm{v}) \quad$ containing $0.5 \%$ pyrogallol $(\mathrm{w} / \mathrm{v})$ for preventing oxidation. The extracts were evaporated to dryness under vacuum at $40^{\circ} \mathrm{C}$ using a rotary evaporator. Extracts were used for gravimetric determination of total lipid.

Sugar analysis: Concentrations of glucose was quantified by HPLC on a Supelcogel $\mathrm{C}-610 \mathrm{H}$ column using a refractive index detector (RID, Schimadzu 10A VP, Kyoto, Japan). Analytes were separated 
at a flow rate of $0.5 \mathrm{~mL} / \mathrm{min}$ with $0.1 \% \mathrm{H}_{3} \mathrm{PO}_{4}$ as eluent at a constant temperature of $30^{\circ} \mathrm{C}$. Prior to analysis, all samples were mixed with $\mathrm{ZnSO}_{4}$ to a final concentration of $10 \%$ to induce protein precipitation. Solid debris was removed by centrifugation (4500rpm for 20min). Sample solutions were squeezed through a $0.20-\mu \mathrm{m}$ filter before column application.

Determination of cell number: Viable cells were determined on Neubauer improved chamber. Samples were continuously drawn from the stirred tank bioreactor and were appropriately diluted in sterile $\mathrm{H}_{2} \mathrm{O}$ and plated on chamber. The number of cells was counted under the light microscope with 400x magnification.

\section{Results and discussion}

E. gracilis mixotrophic cultivation started on the nutrients rich Hutner medium to promote biomass growth. After nutrient (glucose and organic acids) depilation autotrophic condition with $\mathrm{CO}_{2}$ as carbon source stimulated lipid production in the E. gracilis nutrient starvation cells (Figure 1A). Figure 1A show glucose concentration, lipid yields, cell number and biomass concentration changes during photo-mesotrophic batch cultivation in the stirrer tank bioreactor equipped with four aqua-glo lamp. Maximum wavelength was $\lambda \max =160 \mathrm{~nm}$ and given light spectra imitate sunlight. In the first period of photo-heterotrophic growth, E. gracilis used glucose as carbon source. After organic carbon source was depilated conditions for photo-autotrophic growth was established. In the first period of heterotrophic growth, maximal content of lipids in biomass dry weight $\left(\mathrm{Y}_{\mathrm{L} / \mathrm{X}}\right)$ was $0.67 \mathrm{~g} / \mathrm{g}$. In the second cultivation period (96 to $120 \mathrm{~h}$ ), E. graclis used organic acids (malic and gluconic acid) as carbon source. Therefore, significant $\mathrm{pH}$ changes were also detected (Figure 1B). Observed results clearly show diauxic growth of E. gracilis. ${ }^{7}$ Aeration rate and stirrer speed was also changed to promote optimal condition for microalgae cultivation and lipid production (Figure 2A) \& (Figure 2B).

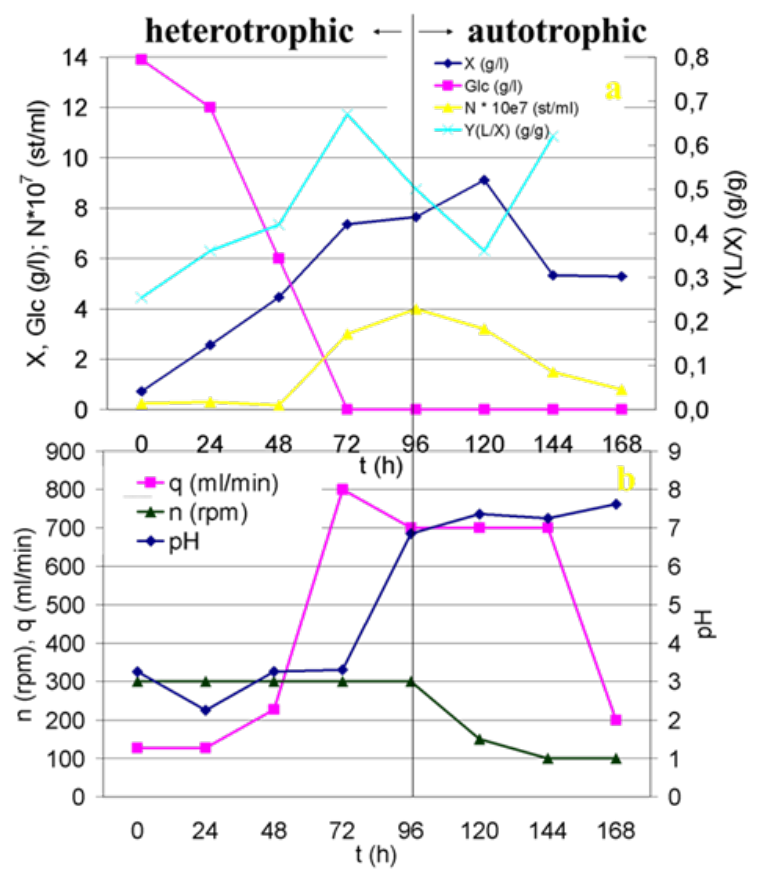

Figure IA \& IB Batch cultivation of $E$. gracilis in medium with I5g// Glc $(\lambda \max =643 \mathrm{~nm})$.
Figure 2A show glucose concentration, lipid yields, cell number and biomass concentration during photo-mesotrophic batch cultivation in the stirrer tank bioreactor equipped with four sun-glo lamp. Maximum wavelength was $\lambda \max =643 \mathrm{~nm}$. Similar trends were observed during first period of photo-heterotrophic growth with sunglo lamps. Changes were marked in the second photo-autotrophic period in which lipid yield increase $30 \%$ in two cultivation days. Provided light source was used to simulate ideal conditions for the photo-autotrophic cultivation and promoted light adsorption in the molecule of chlorophyll. Chlorophyll reaction center with photo system I (P 700) and photo system II are sensitive to the light source wavelength. Therefore lipid syntheses were promoted by light source with maximum wave length similar to photo system I and II..$^{8-10}$ Even so, there is still limitation by the self-shading effect, that is, light penetration decreases as the algal mass increases in the reactor and in the both batches biomass cell number decrease during second autotrophic cultivation period (Figure 1A) \& (Figure 1B).

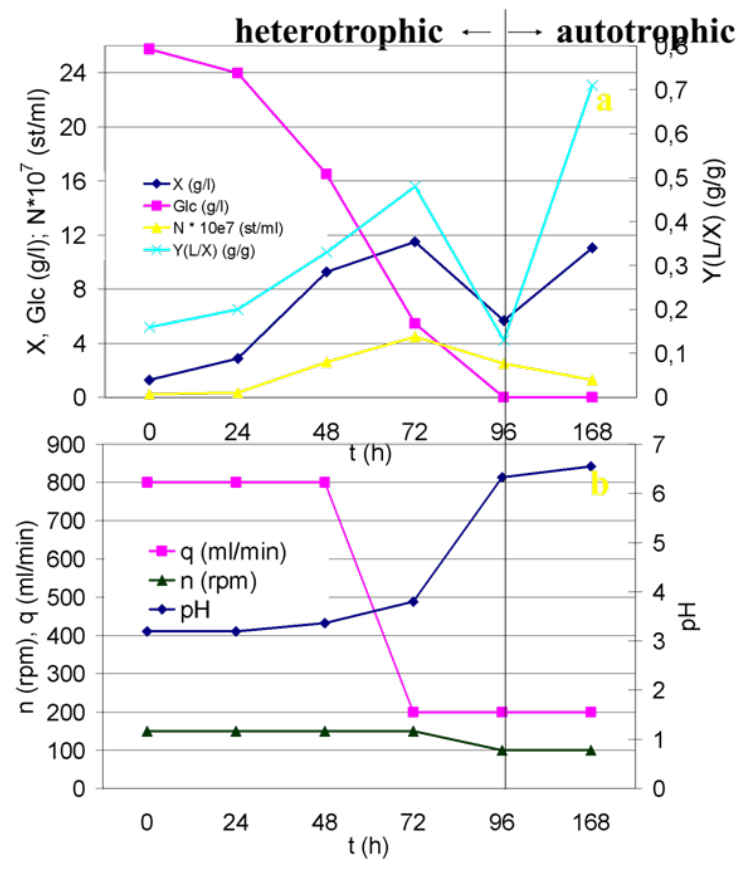

Figure 2A \& 2B Batch cultivation of E. gracilis in medium with $25 \mathrm{~g} / \mathrm{l} \mathrm{Glc}$ $(\lambda \max =160 \mathrm{~nm}$.

\section{Conclusion}

We propose a combination of heterotrophic and autotrophic E. gracilis cultivation for lipids production in a stirred tank Photobioreactor. The growth rate of E. gracilis depended highly on the light intensity and wavelength as well as carbon source composition and concentration. Promising results observed during algae $E$. gracilis photo-mixotrophic cultivation give potential for development of two stage bioprocess where first stage is heterotrophic biomass growth and second autotrophic lipid production from inorganic $\mathrm{CO}_{2}$, respectively.

\section{Acknowledgements}

None.

\section{Conflict of interest}

The author declares no conflict of interest. 


\section{References}

1. Chisti Y. Biodiesel from microalgae. Biotechnol Adv. 2007;25(3):294-306

2. Doran PM. Bioprocess engineering principles. 2nd ed. New York, USA: Academic Press; 2013. p. 751-852.

3. Acien FG, Fernandez JM, Magan JJ, et al. Production cost of a real microalgae production plant and strategies to reduce it. Biotechnol Adv 2012;30(6):1344-1353.

4. Cardozo KHM, Guaratini T, Barros MP, et al. Metabolites from algae with economical impact. Comp Biochem Physiol C Toxicol Pharmacol. 2007;146(1-2):60-78

5. ElMekawy A, Hegab HM, Vanbroekhoven K, et al. Technoproductive potential of photosynthetic microbial fuel cells through different configurations. Renew Sustain Energy Rev. 2014;39:617-627.
6. Singh A, Pant D, Olsen SI, et al. Key issues to consider in microalgae based biodiesel production. Energy Educ Sci Technol A Energy Sci Res. 2012;29(1):563-576.

7. Yu X, Chen L, Zhang W. Chemicals to enhance microalgal growth and accumulation of high-value bioproducts. Front Microbiol. 2015;6:56.

8. Barbosa MJ, Janssen M, Ham N, et al. Microalgae cultivation in air-lift reactors: modeling biomass yield and growth rate as a function of mixing frequency. Biotechnol Bioeng. 2003;82(2):170-179.

9. Masojidek J, Papacek S, Sergejevova M, et al. A closed solar photobioreactor for cultivation of microalgae under supra-high irradiance: basic design and performance. J Appl Phycol. 2003;15(2-3):239-248.

10. Posten C. Design principles of photo-bioreactors for cultivation of microalgae. Eng Life Sci. 2009;9(3):165-177. 